\title{
ANJO NEGRO: SEXO E RAÇA NO TEATRO BRASILEIRO'
}

\author{
Mara Lucia Leal ${ }^{2}$
}

\section{Resumo}

Com este texto proponho uma reflexão sobre o impedimento de um ator negro interpretar o personagem principal da peça Anjo Negro, de Nelson Rodrigues, por ocasião de sua estreia no Rio de Janeiro em 1948. Para tanto, analiso a prática comum dos espetáculos teatrais da época em pintar atores brancos de preto (blackface) para representar personagens negros e o tabu da relação erótico-amorosa entre um homem negro e uma mulher branca tratada de forma magistral pelo autor.

Palavras-chave: Teatro Brasileiro, Anjo Negro, Blackface.

\section{Abstract}

With this text I propose a reflection on the circumstances of a black actor being barred from interpreting the main character of Nelson Rodrigues' play Anjo Negro, on the occasion of its first performance in Rio de Janeiro in 1948. To do so, I analyze the theatrical practice common in those days that white actors represented colored characters with a black facial makeup (blackface) and the taboo of an erotic relationship between a black man and a white woman treated in a masterly way by author's playtext..

Keywords: Brazilian Theatre, Anjo Negro, Blackface. 
Meu Deus do Céu, tenho medo de preto! Tenho medo, tenho medo! ${ }^{3}$

\section{Um homem}

bdias do Nascimento,
negro, ator, artista
plástico, militante da
causa negra e fundador
do Teatro Experimental do Negro (TEN) teve a ideia de criar o grupo depois de assistir, perplexo, a encenação de $O$ Imperador Jones, de Eugene O'Neill, em viagem a Lima, Peru, na qual o personagem título, negro, era representado por um ator branco pintado.

Era 1941 e, tanto no teatro como na sociedade, tentava-se apagar a existência física da cor negra, ou então, apresentála na ficção do piche. Por isso, desde o seu surgimento em 1944, o TEN não era só um experimento teatral, pois além das montagens de espetáculos, o TEN promoveu cursos de alfabetização de adultos, o 1. Congresso do Negro Brasileiro, o Conselho Nacional de Mulheres Negras, o debate sobre a regulamentação do trabalho doméstico, concursos de beleza negra, entre outros.

Apesar do espanto de Abdias, pintar atores brancos de preto era uma prática comum no teatro ocidental até meados do século XX. Para a naturalização dessa atitude dava-se muitas respostas, a principal era a de que não existiriam atores negros capacitados para o palco. Assim, infelizmente, se fazia necessário que um ator capacitado, ou seja, branco, representasse esses papéis.

1 Uma primeira versão desse texto foi apresentada no ENECULT (2008) e na ABRALIC (2008).

2 Atriz/Performer formada pelo CAC/ECA/USP. Professora do Curso de Teatro da Universidade Federal de Uberlândia. Mestre em Artes pela Unicamp com pesquisa sobre o teatro de George Tabori. Doutoranda pelo PPGAC/UFBA com a pesquisa Memória e(m) Performance: material biográfico na composição da cena.

3 Todas as falas das epígrafes pertencem aos personagens da peça Anjo Negro, de Nelson Rodrigues (Ver em RODRIGUES, 1981, p. 121-192)
Entretanto, essa teoria cai por terra quando há um ator negro capacitado para o papel e este é impedido de representálo. Depois de uma luta imensa de Nelson Rodrigues para passar a peça Anjo Negro pela censura brasileira, a "comissão cultural" do Teatro Municipal do Rio de Janeiro, onde a peça iria estrear, proibiu que o personagem principal, Ismael, fosse representado por um ator negro. Ao exigir uma explicação, Nelson Rodrigues ouviu o seguinte: “Se fosse um espetáculo folclórico... E há cenas entre o crioulo e a loura. Olhe - que tal um negro pintado?" (ver em CASTRO, 2003, p. 203). Abdias do Nascimento, grande inspirador do projeto de Nelson Rodrigues em escrever sobre o problema racial no Brasil e para quem ele escreveu Ismael, foi impedido de fazer o papel.

Eu entrei em contato com Anjo Negro e os desdobramentos racistas de sua estreia quando tinha recém chegado a Salvador e buscava me inserir na cena local. Os estudos que fiz para encarnar o papel de Virginia, a mulher subjugada pela violência sexual e pelo desejo reprimido, que mata os filhos negros como meio de salvação, me ajudaram a refletir sobre as relações raciais que vivia no dia-a-dia da cidade.

Ao estudar a peça de Nelson Rodrigues, classificada como tragédia pelo autor, e o período em que foi escrita, me chamou muito a atenção o ato discriminatório do blackface. Assim, sem me furtar das relações estreitas entre a arte e os condicionamentos históricos e sociais que a cercam, no caso em questão, pretendo focar nos preconceitos da época, construídos historicamente, que geraram tal procedimento artístico, a despeito de toda uma corrente de artistas, como o próprio Abdias do Nascimento e Nelson Rodrigues, que lutava ativa e artisticamente contra essas práticas. A chave de minha interpretação vem do próprio texto: o tabu da relação eróticoamorosa entre um homem negro e uma mulher branca tratada de forma magistral por Nelson Rodrigues.

Sempre o sonho dele foi violar uma branca. 


\section{Um personagem}

Ismael, negro, médico. Segundo seu irmão Elias, Ismael sempre quis ser branco: "Desde menino tem vergonha; vergonha, não, tem ódio da própria cor". Ismael nega suas origens para tentar ser aceito no mundo branco; ao ser rechaçado subjuga, através do poder sexual, uma mulher branca - Virgínia - com quem tem três filhos. A tentativa de branqueamento de sua prole é duplamente frustrada: seus filhos são negros como ele e, por isso, assassinados pela mãe que não suporta ver em sua descendência o reflexo do marido.

Frantz Fanon, no mesmo período em que estreava Anjo $\mathrm{Negro}^{4}$, discorria sobre o perigo de dois caminhos antagônicos que o negro tem a sua frente, na tentativa de resolver esse problema. Ao aceitar as diferenças impostas pela sociedade branca e colonizadora, há dois caminhos: ambicionar ser branco, alienando-se, para ser aceito pela sociedade ou exaltar sua negritude. Em sua opinião, os dois caminhos estão fadados ao fracasso. Sobre o primeiro, não há necessidade de argumentos; sobre o segundo, a questão é complexa: a valorização da negritude se dá, muitas vezes, pela exaltação de valores que a cultura branca impôs sobre ela, como o excesso sexual e sensual, a brutalidade física, etc. Sobre isso Fanon conclui:

Eis na verdade o que se passa: como percebo que o preto é o símbolo do pecado, começo a odiá-lo. Porém constato que sou negro. Para escapar ao conflito, duas soluções. Ou peço aos outros que não prestem atenção à minha cor, ou, ao contrário, quero que eles a percebam. Tento, então, valorizar o que é ruim - visto que, irrefletidamente, admiti que o negro é a cor do Mal. Para pôr um termo a esta situação neurótica, na qual sou obrigado a escolher uma solução insana, conflitante, alimentada por fantasmagorias, antagônica, desumana enfim, - só tenho uma solução: passar por cima deste

4 Fanon lançou Peau Noire, Masques Blancs em 1952, na França; Nelson Rodrigues estreou com Anjo Negro em 1948, no Teatro Felix, no Rio de Janeiro com direção de Ziembinski. drama absurdo que os outros montaram ao redor de mim, afastar estes dois termos que são igualmente inaceitáveis e, através de uma particularidade humana, tender ao universal (FANON, 2008, p.166).

Rodrigues afirma que escreveu Anjo Negro porque achava um absurdo o negro ser representando no teatro apenas como o "moleque gaiato" das comédias de costumes ou por tipos folclorizados. Por isso, cria um personagem - Ismael - de classe média, inteligente, mas também com paixões e ódios, ou seja, "um homem, com dignidade dramática", enredado em situações proféticas e míticas (Ver em CASTRO, 2003, p. 203). Mas Ismael, tragicamente, esta envolvido na dupla situação neurótica a qual descreve Fanon: rechaça suas origens e exerce violência sexual para pertencer ao mundo dos brancos.

Nelson Rodrigues, em várias ocasiões, afirma ter escrito o personagem para seu amigo Abdias representar, pois, segundo ele, era o "único negro do Brasil". Em uma de suas crônicas sobre a vinda de Sartre ao Brasil, nas quais Nelson comenta que o filósofo sempre perguntava aos presentes - "Onde estão os Negros?", numa irônica cutucada ao fato de a burguesia carioca ser composta apenas por brancos, o cronista emenda: "Alguém poderia dizer a Sartre, sem violentar a verdade: - 'Temos aí um negro, um único negro, o Abdias do Nascimento'. E, de fato, que eu saiba, é o nosso único negro confesso e radiante de o ser. A cor, em Abdias, é uma perene tensão dionisíaca" (RODRIGUES, 2003, p. 51). Mas, a despeito de trazer o personagem negro para outro patamar da dramaturgia brasileira, Rodrigues talvez não tenha previsto que estava tratando de um tema tabu: o amor erótico inter-racial entre um homem negro e uma mulher branca.

A peça estreou em 1948, com Ismael pintado de graxa, representado pelo ator Orlando Guy, Virgínia pela atriz Maria Della Costa e sob direção de um Ziembinski que, em 1943, havia revolucionado o teatro brasileiro com sua encenação de Vestido de Noiva, mas que não ousou mais essa 
revolução teatral, votando também pela cara pintada. Abdias foi uma das pessoas que convenceu Nelson de que seria melhor encená-la assim do que não ir para os palcos. De fato, parece que Nelson foi o único a se incomodar, pois nenhum jornal do período questionou a ausência de um ator negro no palco.

Depois da estreia, entre a crítica calorosamente dividida havia os entusiastas como Menotti del Picchia e os detratores que chegaram a listar todos os crimes cometidos pelos personagens: "homicídios com agravantes, indução a lascívia, três infanticídios, adultério, corrupção de menor, lesões corporais graves, estupro e cárcere privado". Mas o problema central da peça não seria o relacionamento entre um homem negro e uma mulher branca, mas outro: "Sexo, sexo, sexo, é só nisso que ele pensa?", escrevera um crítico da época (ver em CASTRO, 2003, p. 202).

\footnotetext{
Já me esqueci dos outros homens, já sinto como se no mundo só existisse uma fisionomia - a sua - todos os homens só tivessem um rosto - o seu.
}

\section{Blackface}

A prática de pintar atores brancos de preto foi muito recorrente nos Estados Unidos durante mais de um século nos Minstrel Shows. O auge desses espetáculos ocorreu entre a década de vinte do século XIX e a de trinta do século XX. ${ }^{5}$ Tratavase de shows humorísticos, onde havia comediantes brancos que se travestiam de homens negros: pintavam o rostocom graxa, exageravam os lábios, usavam perucas de lã, luvas e fraque. Essas performances desempenharam papel importante em consolidar e proliferar imagens, atitudes e percepções racistas no mundo. Era também

\footnotetext{
5 Há pouco material a respeito publicado em português. Encontrei um livro sobre a história do Jazz que discorre sobre os Minstrel Shows. Ver em Calado, 1990.
}

uma forma de se apropriar, assimilar e explorar a cultura negra norte-americana.

Tratando especificamente do "travestismo racial", 6 no caso do blackface, quando o homem branco se fantasia de homem negro, Senelick (2000, p. 300) considera que assim como no travestismo de gênero, o de raça também estaria baseado no desejo sexual. Para ele, "a psicologia das relações raciais são muito emaranhadas de desejo sexual, particularmente em manifestações como de dominação e submissão, de exotismo e de atração pela oposição".

Porém, em 1849, surgem comediantes negros fazendo blackface e em 1860 já havia vários grupos só com comediantes negros. Esses grupos fizeram muito sucesso e incluíram dança e música da cultura afro-americana nos shows, passando assim a rivalizar com os grupos de comediantes brancos, autodenominandose os "autênticos". Esses performers faziam auto-paródia bufonescas, mas também, apesar da origem discriminatória e preconceituosa desses shows, criaram um espaço de resistência e de trabalho para artistas que tinham dificuldades de se inserirem em outras atividades do mundo artístico norte-americano. Outra novidade que esses "verdadeiros" blackface inseriram no Minstrel Show foi a participação de mulheres, o que, segundo Senelick (2000, p. 299), trouxe uma "erotização" para esses eventos, principalmente se considerar o papel que a mulher negra tem no imaginário masculino norte-americano.

No Brasil não há notícia sobre eventos dessa natureza, mas os negros e mulatos já atuavam em autos profanos como a Congada e danças dramáticas desde a metade do século XVI. Pode-se ver ainda hoje personagens negros no Bumbameu-boi e no Cavalo Marinho, muitas vezes com a cara pintada, que poderiam ser considerados, inclusive, o germe dos "negrinhos pitorescos das comédias

6 É Michael Rogin quem traz a ideia de que o blackface seria uma forma de "travestismo racial". Ver em SENELICK, 2000 , p. 300. 
de costumes" (MENDES, 1993, p. 48). Uma performance que pode-se chamar de blackface à brasileira é Nego Fugido, apresentada por negros exageradamente pintados, realizada em Acupe de Santo Amaro, na Bahia que, como o próprio nome sugere, representa a fuga de escravos.

Na segunda metade do século XVIII já havia várias companhias profissionais de negros e mulatos, tanto escravos como libertos, que representavam adaptações de textos europeus com o rosto e as mãos pintados de branco, realizando uma inversão do blackface norte-americano. Entretanto, paradoxalmente, com a criação de um teatro nacional em 1838, ou seja, com dramaturgia, elenco e produtores brasileiros, os atores negros e mulatos sumiram da cena teatral. Apesar de saírem da cena como atores, eles permanecem como personagens, fato que definha com a abolição da escravatura e passa por momentos sombrios até meados do século $X X^{7}$, quando tanto o TEN como dramaturgos do calibre de Nelson Rodrigues, Antônio Callado, entre outros, tentam reverter esse quadro toscamente pintado (MENDES, 1993).

Ainda sobre o período escravagista, pode-se citar a dramaturgia de José de Alencar, autor que cria personagens negros importantes em suas peças: Pedro, da comédia O Demônio Familiar (1858) e Joana, a protagonista do drama A Mãe (1860). A inclusão de temas como a escravidão na nascente dramaturgia brasileira faz parte, segundo Flávio Aguiar (1984), de um movimento de valorização do "eu nacional" surgido com a independência do Brasil. Segundo o autor, a comédia, em seu processo de rebaixamento do "outro" para atingir seu fim e de afirmação do "eu nacional" teria se concentrado em ridicularizar três outros: $\mathrm{O}$ primeiro seria a antiga metrópole; o segundo as nações

7 Em 1926 De Chocolat, influenciado pelas Revistas Negras parisienses, cria no Rio de Janeiro a Companhia Negra de Revistas. A iniciativa, apesar de durar apenas um ano, trouxe à tona, através da comicidade tão comum ao estilo das revistas, a discussão sobre os preconceitos raciais no Brasil. Ver em Barros (2005). civilizadas como a França e o terceiro outro seria o ridículo do "eu nacional", ou seja, o triste legado colonial. Dentro desse terceiro outro estaria a mediocridade, a pobreza e em seu centro a escravidão, o "mal necessário".

Aguiar não faz nenhuma menção de como essas peças foram representadas nesse período e quem foram os atores, pois seu foco é a dramaturgia e sua recepção da época, mas não é difícil imaginar como e por quem esses personagens negros foram representados num Brasil escravocrata: atores e atrizes brancos pintados.

Lilia Schwarcz (1987, p. 244), em estudo sobrecomoohomemnegroerarepresentado nos jornais paulistas do final do século XIX, salienta que a esse "outro" "violento e degenerado" do período escravagista, inclui-se o de "estrangeiro indesejável" com o fim da escravidão. Pois, é ao se "assumir as diferenças", "ao por em relevo o lado estrangeiro", " ou ao se eleger a 'cor' ou os caracteres hereditários como critérios 'dignos' e eficazes para a delimitação da degeneração e da desigualdade entre as raças que se estabelecem com maior clareza o contraste e a distinção".

Entretanto, a partir do início do século $X X$ essa questão vai sumindo da pauta, vai sendo apagada dos jornais que passam a assumir o discurso da "harmonia racial" e os preconceitos, ao não serem mais nomeados, passam para o "local do implícito, do consenso, do silêncio" (SCHWARCZ, 1987, p. 256). Do mesmo modo, vemos o apagamento do ator e do personagem negro dos palcos brasileiros. E esse apagamento se dá, muitas vezes, através de uma demão de tinta preta.

A branca também desejou o preto.

\section{Cor e desejo}

Há no imaginário brasileiro, principalmente do homem branco, quando se trata de relacionamentos heterossexuais inter-raciais, em se pensar apenas no casal 
homem branco/mulher negra, na verdade, mulata. Há inúmeros trabalhos sociológicos a respeito e tanto na literatura como nas artes e nos meios de comunicação temos personagens mulatas como a Gabriela de Jorge Amado, povoando o imaginário masculino. No entanto, quando vamos para os números, eles nos informam que a maioria dos relacionamentos inter-raciais no Brasil é constituída pelo casal homem negro/mulher branca. ${ }^{8}$ Por que esse fato povoa tão pouco nossas representações?

Segundo Laura Moutinho (2003, p. 167), essa relação é considerada tabu em nossa sociedade porque ameaçaria o domínio masculino branco da estrutura de dominação social e econômica. Por isso, no "plano das representações, a estrutura escolhida para a decantada miscigenação brasileira é composta pelo homem 'branco' com sua esposa 'branca' e a amante 'negra' /'mestiça'".

Se atentarmos para a tese ficcional do branqueamento, ela funcionaria apenas dentro do par homem branco/ mulher negra: É o português colonizador gerando descendentes na barriga negra, descendentes que a cada geração ficariam mais claros. Quando se inverte a posição, é o negro gerando descendência na barriga branca: os filhos de Ismael com Virgínia serão sempre negros como o pai. Moutinho analisa sete obras da literatura brasileira, entre o final do século XIX e meados do XX, detendo-se sobre as relações afetivosexuais inter-raciais. ${ }^{9}$ Há tanto os pares homem branco/mulher negra, como o seu inverso, além de uma relação homossexual homem branco/homem negro. Em todas se vê a dificuldade enfrentada pelos amantes: Dos nove casais analisados, só

8 Esses dados foram analisados a partir do senso demográfico de 1980 . Os casamentos endogâmicos representam $79 \%$ do total. Dos $21 \%$ restantes tem-se $57 \%$ de homens com pele mais escura que as mulheres e $42,5 \%$ de mulheres mais escuras que os homens. Ver em SILVA, 1987. p. 54-84.

9 Trata-se de $O$ Mulato $O$ Cortiço, de Aluísio Azevedo; $O$ Bom Crioulo, de Adolfo Caminha, considerado o primeiro romance homossexual da literatura brasileira; Jubiabá e Gabriela, Cravo e Canela, de Jorge Amado; as peças Sortilégio, de Abdias do Nascimento e Anjo Negro, de Nelson Rodrigues. três permanecem juntos no final da obra; os outros seis terminam por assassinato ou suicídio do parceiro.

Uma das obras em questão é Anjo Negro, com a qual quero retomar a discussão sobre aos motivos do impedimento de Abdias do Nascimento em fazer o papel de Ismael: "o crioulo com a loura", segundo os censores. A peça fala de desejo, do desejo proibido do negro pela branca: "Oh! Deus mata todos os desejos! Maldita seja a vida, maldito seja o amor!" é a imprecação do coro das velhas negras em volta do caixão do terceiro "anjo negro", vítima dessa união funesta. Virgínia seria uma mulher branca de útero negro, segundo as carpideiras, remetendose tanto a cor do filho que carrega no ventre como a cor da morte.

NelsonRodriguescriaumadramaturgia na qual o contraste branco/negro será o tempo todo colocado em relevo como o impedimento da relação. Não importa que Ismael seja de classe social igual à de Virgínia, que tenha bens suficientes para manter mulher e filhos, pois é a negação da sua cor, tanto por ele como por Virgínia, que impossibilita a união e a geração de descendentes; é essa negação que gera a maldição da mãe negra, trazida por Elias, irmão de criação branco e cego como o mensageiro dos deuses das tragédias gregas, Tirésias.

Ismaeltentaapagaromundodosbrancos de sua relação com Virgínia, que não pode sair de casa, nem ver ninguém: "Só posso esperar você. [...] O mundo está reduzido a nós dois - eu e você". Mas essa também foi uma escolha dela, pois não queria ser mais vista depois do que aconteceu ali, na cama de solteiro permanentemente presente como naquele dia passado: o estupro. $\mathrm{O}$ segredo dessa relação está fundado no abuso sexual sofrido por Virgínia, tanto na primeira noite como em todas que tem com o marido: o ato sexual entre o homem negro e a mulher branca visto como uma constante violação.

Só no final da peça, quando é preterida por Ismael, Virgínia afirma que também sempre o desejou, um desejo cultivado 
desde a infância, quando viu homens negros seminus carregando um piano na rua. Aquele desejo proibido pelo outro, o negro, foi constantemente mantido em segredo, até para ela mesma. Somente quando Ismael a troca pela filha é que ela consegue trazer a tona o que mantinha na escuridão: o desejo pelo homem negro.

Entretanto, apesar do desejo, ou até por causa dele, as carpideiras encerram a peça vaticinando o impedimento da geração de filhos. Depois do casal se reconciliar e consumar o ato sexual, elas concluem: "Futuro anjo negro que morrerá como os outros", diz uma e a outra completa: "Vosso amor, vosso ódio não tem fim neste mundo. Branca Virgínia. Negro Ismael". Fim do último ato.

Nelson Rodrigues, ao nos apresentar essa relação impossível, expõe de forma crua e poética dois grandes preconceitos: o racial contra as pessoas de pele negra, tanto pelos que a tem (Ismael) como por quem o gera (Virgínia). O outro é sobre a mulher branca, cuja função é manter a espécie e suprimir os desejos.

Ann Pelegrini (2001), ao trazer a teoria da interpelação de Althusser para a constituição sexual do sujeito: "É uma menina", me ajuda a refletir sobre a interpelação racial: "Olha, um negro!", como descreve Fanon (2008). Tanto Ismael como Virgínia foram constituídos por essas interpelações. Por um momento não ouviram o chamado e se desejaram. Mas o chamado não pára nunca e ambos acabam olhando para trás e se identificam com ele. Segundo Fanon (2008), o homem negro passa por dois complexos de inferioridade: o econômico e o epidérmico. Ismael consegue romper com o primeiro, mas o segundo lhe persegue sempre, por isso, vê como única saída a alienação de sua cor, o desejo de ser branco através de Virgínia e sua descendência. Virgínia, a moça branca de classe média, criada para o "bom casamento" e para a perpetuação da espécie, primeiro deseja o noivo da prima, depois deseja o marido negro. Resultado: Anjos negros. Uma mulher branca, da década de quarenta do século passado, não poderia ter desejo e ser mãe ao mesmo tempo, principalmente mãe de uma prole negra.

Apesar de o autor explicitar ao longo da peça que é o preconceito racial o gerador de toda a tragédia vivida pelos personagens, é curioso - talvez fosse melhor dizer um curioso sintoma - observar que tanto a crítica da época silencia sobre essa questão, como também Sábato Magaldi, em sua introdução a uma das edições da peça, afirma que devido ao seu caráter "hermético", Anjo Negro não "arregimenta motivos racionais para discutir o problema racial (...)", pois Nelson Rodrigues só estaria chamando os espectadores a se depararem com "seus mitos ancestrais". (ver em RODRIGUES, 1981, p. 30) Pode até ser, mas então esse chamado seria para se depararem com o mito ancestral da diferença racial.

É para tentar desconstruir cenas como essas que surge o Teatro Experimental do Negro. Segundo Abdias do Nascimento, o TEN surgiu como uma iniciativa de contra-ação ás práticas citadas. Portanto, o objetivo artístico do TEN era fomentar uma nova dramaturgia ligada aos temas afro-brasileiros e produzir espetáculos, nos quais os atores negros tivessem espaço para atuar. Para alcançar tal objetivo o grupo também precisava formar atores. Assim, a partir de um viés artístico, o TEN promoveu uma revolução social, pois a maioria de seus integrantes era oriunda das classes populares, como empregadas domésticas e operários, e muitos deles sem alfabetização.

Ironildes Rodrigues (1998), professor dos cursos de alfabetização promovidos pelo TEN que chegaram a ter 600 alunos, relata que além das aulas de português, história e matemática, os alunos também aprendiam história do teatro e folclore brasileiro. $\mathrm{O}$ aprendizado era incentivado por leituras, ensaios e discussões de peças, como O Imperador Jones de Eugene O`Neill, peça de estreia do TEN no Teatro Municipal do Rio de Janeiro, em 1945. 
Onze anos depois, em 1956, vários atores do grupo participam da montagem de Orfeu da Conceição, de Vinícius de Moraes, primeira peça de autor brasileiro com elenco exclusivamente negro a se apresentar no mesmo teatro, além de ter como cenário um morro carioca e temas populares como capoeira e samba: "Mais que um acontecimento teatral, o Orfeu foi um excitante momento cultural na vida da cidade e, sem exagero, do país, pois nesta peça teve início a parceria Vinícius e Tom [Jobim], que resultou na Bossa Nova", declara Haroldo Costa, ex-ator do TEN que fez o papel de Orfeu na montagem. (COSTA, 2004, p. 225).

Nesses sessenta anos que nos separam dessas atividades pioneiras no âmbito das artes cênicas para a inclusão na cena de uma parcela da população brasileira relegada à margem dos produtos artísticoculturais muitas coisas mudaram, outras nem tanto. Além dos atores formados no grupo, como Ruth de Souza, Lea Garcia, Haroldo Costa e Aguinaldo Camargo, que seguiram trabalhos individuais ou montaram seus próprios grupos, criou-se uma rede de parcerias e influências que chega até os dias de hoje, apesar do hiato existente durante o período da ditadura brasileira que sufocou as atividades do TEN e de tantos outros.

Dentro do que comumente se passou a chamar de "Teatro Negro" há alguns grupos considerados "herdeiros" do TEN. Além de influências diretas como a criação do TEN de São Paulo, que seguiu os moldes do grupo do Rio, encenando, inclusive, os mesmos textos e incluindo autores como Augusto Boal, destaca-se o grupo Brasiliana, fundado por Haroldo Costa a partir de uma dissidência com o TEN, pois se queria dar mais ênfase a cultura afro-brasileira a partir da dança e música, realizando trabalhos a partir das manifestações populares.
Em 1966, Milton Gonçalves junto com Antônio Pitanga, Zózimo Bubul, entre outros, forma o Grupo Ação, cujo foco era o Teatro de Rua, pensando em atingir seu público alvo: o negro. Lea Garcia, ex-atriz do TEN também organiza um grupo dentro do IPCN (Instituto de Pesquisas das Culturas Negras), entre 1978 a 1980. Um dos trabalhos realizados foi a peça Chico Rei, de Walmir Ayala, que posteriormente foi adaptada para o cinema, com Mário Gusmão no papel principal.

Atualmente, existem vários grupos com essas características pelo Brasil, como destaca o trabalho de Douxami (2001) e também como pude observar durante o II Encontro de Performance Negra, realizado em 2009, no teatro Vila Velha, em Salvador, onde estavam representados por volta de cem grupos de teatro e dança de todo o país.

Uma questão que se coloca a partir dessa realidade é: Por que ainda se faz necessário no Brasil a criação de grupos nos moldes do Teatro Experimental do Negro, onde a ideia de diferença racial é a geradora desses grupos? Talvez simplesmente porque no Brasil ainda se acha estranho "Hamlets" e "Prósperos" negros como Peter Brook já o fez com sua companhia internacional. Talvez porque ainda ao se escolher um ator para determinado papel, a cor/raça é critério de escolha ou veto apesar da mídia e do senso comum alardearem que não existe racismo no Brasil.

A despeito de muitos desses grupos receberem críticas de que a militância, o social ou o político, às vezes, estão à frente de questões artísticas, não posso deixar de concordar com Abdias que "a política é totalmente implicada em qualquer atividade cultural" (apud DOUXAMI, 2001, p.323), por isso, todoato, inclusiveoartístico, é político. As escolhas estéticas que faço estão em sintonia com a visão de mundo que tenho, com questões identitárias e de alteridade que, no caso brasileiro, se constrói também a partir desses mitos raciais. 


\section{Referências bibliográficas}

AGUIAR, Flávio. A comédia nacional no teatro de José de Alencar. São Paulo: Ática, 1984.

BARROS, Orlando de. Corações de Chocolat: A história da Companhia Negra de Revistas (1926-27). Rio de Janeiro: Livre Expressão, 2005.

CALADO, Carlos. O Jazz como espetáculo. São Paulo: Perspectiva, 1990.

CASTRO, Ruy. O anjo pornográfico. São Paulo: Companhia das Letras, 2003.

COSTA, Haroldo. Onegro nas artes cênicas. In: História do negro no Brasil. Brasília: Fund. Palmares/MinC, Vol. 1, 2004, pp. 205-261.

DOUXAMI, Christine. Teatro Negro: a realidade de um sonho sem sono. In: AfroÁsia, n. 25-26, 2001, pp. 313-363.

FANON, Frantz. Pele negra, máscaras brancas. Tradução de Renato da Silveira. Salvador: EDUFBA, 2008.

MENDES, Mirian Garcia. O negro e o teatro brasileiro (entre 1889 e 1982). SP: Hucitec; RJ: IBAC; Brasília: Fundação Cultural Palmares, 1993.

MOUTINHO, Laura. Razão, "cor" $e$ desejo: uma análise comparativa sobre relacionamentos afetivo-sexuais "interraciais" no Brasil e na África do Sul. São Paulo: UNESP, 2004.

NASCIMENTO, Abdias. (Org.) Teatro Experimental do Negro: Testemunhos. Rio de Janeiro: Edições GRD, 1968.

. et alli. Quilombo: vida, problemas e aspirações do negro. Edição fac-similar do jornal dirigido por Abdias do Nascimento. Introdução de Antonio Sergio Alfredo Guimarães. São Paulo: Fundação de Apoio à USP; Ed. 34, 2003.

PELLEGRINI, Ann. Laughter. In: Psychoanalysis and Performance. Patrick Campbelle Adrian Kear (org.). NY, London: Routledge, 2001, pp. 177-191.

RODRIGUES, Ironildes. Diário de um negro atuante (1974-1975). In: Thot, Revista do Gabinete do Senador Abdias do Nascimento, n. 5, 1998, pp. 210-211.
RODRIGUES, Nelson. Onde estão os negros? In: O óbvio ululante. São Paulo: Companhia das Letras, 2003.

Teatro completo de Nelson Rodrigues.

Peças míticas. Organização e introdução de Sábato Magaldi. Rio de Janeiro: Nova Fronteira, 1981.

SCHWARCZ, Lilia Moritz. Retrato em branco e negro: jornais, escravos e cidadãos em São Paulo no final do século XIX. São Paulo: Companhia da Letras, 1987.

SENELICK, Laurence. Putting on the drag. In: The changing room: sex, drag and theatre. London; New York: Routledge, 2000, pp. 295-325.

SILVA, Nelson do Valle. Distância social e casamento inter-racial no Brasil. In: Estudos Afro-Asiáticos, n. 14, 1987, pp. 54-84. 